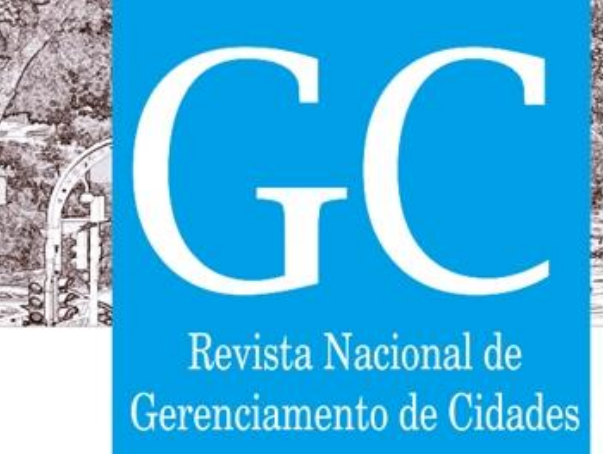

ISSN 2318-8472

v. 08, n. 60,2020

\title{
Estratégias internacionais e tecnologias de gestão da arborização urbana.
}

International strategies and technologies for urban afforestation management.

Estrategias y tecnologías internacionales para la gestión de la forestación urbana.

José Augusto Ribeiro da Silveira

Professor Doutor, UFPB, Brasil

ct.laurbe@gmail.com

Larissa Ellen de Oliveira Lima

Mestranda em Arquitetura e Urbanismo, UFPB, Brasil

lariellen12@hotmail.com

Juliana Xavier Andrade de Oliveira

Mestranda em Arquitetura e Urbanismo, UFPB, Brasil jx.andrade@gmail.com 


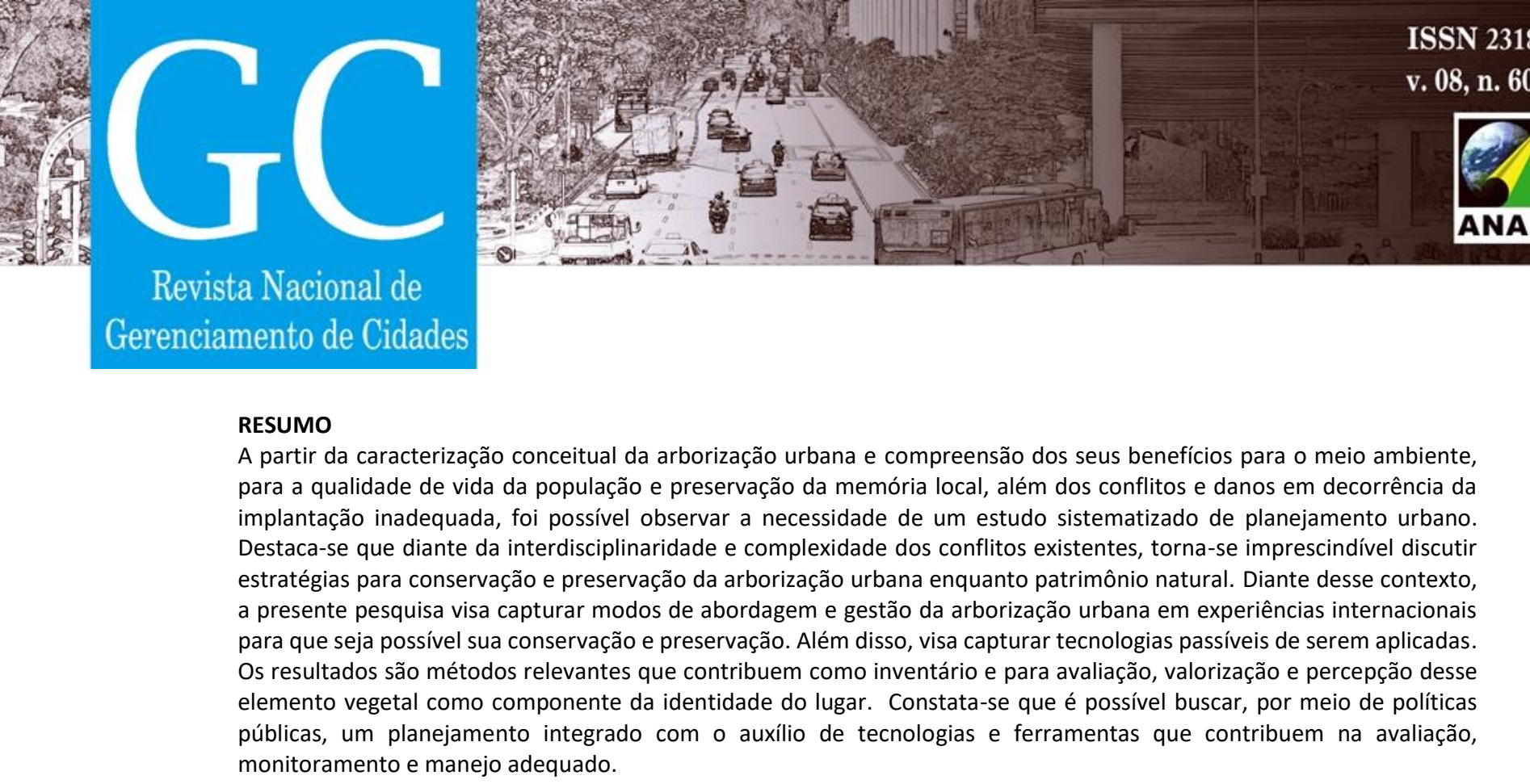

PALAVRAS-CHAVE: Arborização Urbana. Gestão. Tecnologias.

\begin{abstract}
Starting from the conceptual characterization of urban afforestation and understanding of its benefits for the environment, for the quality of life of the population and preservation of local memory, as well as considering the conflicts and damage due to inadequate implantation, it was possible to observe the need for a systematized study of urban planning. It is worth highlighting that in the face of the interdisciplinarity and complexity of existing conflicts, it is essential to discuss strategies for the conservation and preservation of urban afforestation as a natural heritage. In light of this context, the present research aims to capture ways of approaching and managing of urban afforestation in international experiences so that it is possible to conserve and preserve it. It also aims to capture the technologies that can be applied. The results are relevant methods that contribute as an inventory and to the evaluation, valuation and perception of this vegetal element as a component of the identity of the place. It can be noted that it is possible to seek, through public policies, an integrated planning with the help of technologies and tools that contribute to the assessment, monitoring and proper management.
\end{abstract}

KEYWORDS: Urban afforestation. Management. Technology.

\title{
RESUMEN
}

Partiendo de la caracterización conceptual de la forestación urbana y la comprensión de sus beneficios para el medio ambiente, la calidad de vida de la población y la preservación de la memoria local, además de los conflictos y daños debidos a una implantación inadecuada, fue posible observar la necesidad de un estudio sistemático de la planificación urbana. Cabe destacar que, en vista de la interdisciplinariedad y complejidad de los conflictos existentes, es esencial discutir estrategias para la conservación y preservación de la forestación urbana como patrimonio natural. Dado este contexto, la presente investigación tiene como objetivo capturar formas de abordar y gestionar la forestación urbana en las experiencias internacionales para que sea posible conservarla y preservarla. Además, tiene como objetivo capturar tecnologías que se puedan aplicar. Los resultados son métodos relevantes que contribuyen como inventario y también para evaluación, valoración y percepción de este elemento vegetal como componente de la identidad del lugar. Parece que es posible buscar, mediante políticas públicas, una planificación integrada con la ayuda de tecnologías y herramientas que contribuyan a la evaluación, el seguimiento y la gestión adecuada.

PALABRAS CLAVE: Forestación urbana. Administración. Tecnología. 


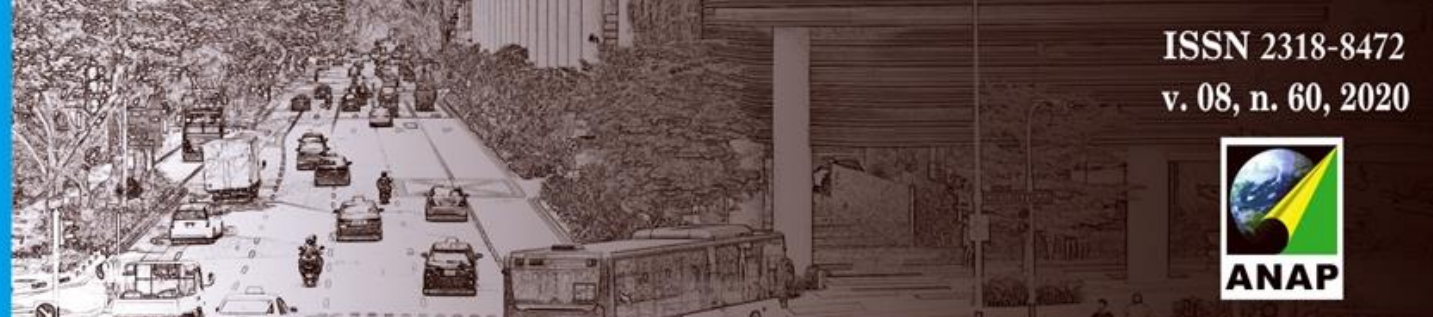

Revista Nacional de

Gerenciamento de Cidades

\section{INTRODUÇÃO}

A presente pesquisa tem como foco principal discutir o planejamento da arborização urbana e as ferramentas tecnológicas para sua gestão, por intermédio da captura de estratégias adotadas internacionalmente. Dessa forma, inicia-se com a caracterização conceitual da arborização urbana, compreendendo seus benefícios e, por outro lado, possíveis danos ocasionados em decorrência da falta de planejamento urbano.

Segundo Lima et al (1994) arborização urbana engloba os elementos vegetais de porte arbóreo existentes dentro da cidade. Também é entendida como um conjunto de terras públicas ou privadas com vegetação predominantemente por árvores que uma cidade apresenta ou, similarmente, é um conjunto de vegetação arbórea natural ou cultivada que uma cidade possui em áreas particulares, praias, parques e vias públicas (SANCHOTENE, 1994; SILVA JUNIOR e MÔNICO, 1994). As árvores plantadas em calçadas fazem parte da arborização urbana e sua contribuição é contabilizada na cobertura vegetal. A arborização predomina em três esferas distintas de uso e responsabilidade: (1) ao longo de vias; (2) em áreas livres de uso público e potencialmente coletivas, e (3) além de lotes de propriedade privada (EMBRAPA, 2000 apud RIBEIRO, 2009).

A vegetação urbana é responsável por uma série de benefícios de cunho social, como a potencialização do uso dos espaços livres públicos pelo sombreamento e consequente "bem-estar" físico e psicológico proporcionado aos usuários, e o benefício ambiental, a exemplo da sua influência na estabilidade do microclima urbano, garantia da qualidade do ar nas cidades e controle e absorção das águas pluviais.

As condições do meio ambiente podem exercer influência direta no campo da psicologia social. Estudos realizados por Miana (2010 apud MARUYAMA e SIMÕES, 2014), e citados por Gomes e Soares (2003), destacam a capacidade da arborização em influenciar o estado de ânimo dos seres humanos que habitam o meio urbano, onde estes se mostram mais amistosos, cooperativos, menos deprimidos e afetados pelo estresse característico dos grandes centros, além de muito mais propensos às atividades de convívio, exercícios físicos e lazer.

No entanto, também se observa uma sequência de conflitos e danos à infraestrutura urbana em decorrência da arborização inadequada, como a deterioração ou inviabilização do passeio público e conflitos com as redes elétrica e de esgoto. A arborização urbana no Brasil, em sua grande maioria, tem se realizado sem planejamento adequado. Dessa forma, a arborização de ruas, por exemplo, requer para efetivação dos benefícios esperados, que seja adequadamente planejada e mantida de forma sustentável, considerando além dos benefícios ambientais inerentes ao tema os aspectos econômicos, políticos e sociais (MILANO, 1994). Embora as árvores possam ser encontradas em vários ambientes urbanos, a rua se apresenta como o local tradicional da arborização urbana, onde as árvores são plantadas enfileiradas nas calçadas (GONÇALVES e PAIVA, 2004), geralmente dispensando planejamento prévio e manutenção adequada (RACHID e COUTO, 1999) e por vezes com escassa legislação específica.

As deficiências do planejamento na implantação e na manutenção da arborização urbana ocasiona 


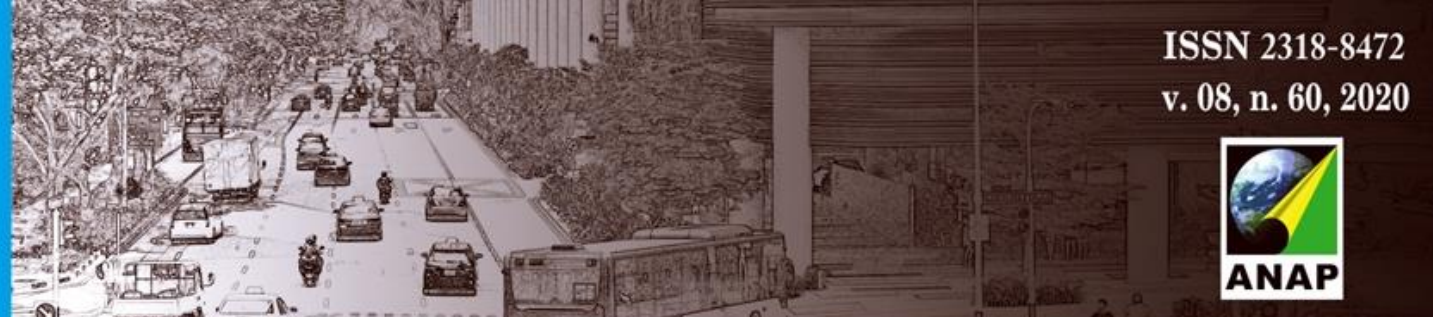

Revista Nacional de

Gerenciamento de Cidades

problemas tais como: diversidade reduzida de espécies (McPHERSON, 2003), uso excessivo de espécies exóticas (BIONDI e MACEDO, 2008) e manutenção deficiente (RACHID e COUTO, 1999; SILVA FILHO et al., 2002), o que acarretam conflitos entre as árvores e os elementos urbanos construídos (VELASCO et al., 2006). Por este motivo, a vegetação urbana tem sido incorporada às discussões sobre os espaços públicos para além do recurso paisagístico e da estética do urbano, mas também como ferramenta para garantir o usufruto destes espaços pela população, atraída pelas condições ambientais proporcionadas e pelas emoções próprias que o verde urbano acarreta.

Deve-se ter o entendimento da vegetação como elemento urbano que merece atenção, seja a massa vegetal existente ou a ser implementada, e deve figurar como recurso de projeto para garantir a identidade do lugar e a própria eficácia das soluções e dos usos propostos na esfera do projeto.

Em suma, quando observadas as reflexões propostas, a natureza multifacetada do tema e a complexidade dos conflitos que vão desde questões conceituais à prática cotidiana do planejamento, torna-se imprescindível discutir estratégias para gestão e conservação, assim como as ferramentas e tecnologias que podem ser aplicadas nesse processo.

\section{CAPTURA DE ESTRATÉGIAS INTERNACIONAIS: PLANEJAMENTO, GESTÃO E CONSERVAÇÃO}

Para que a gestão da arborização no meio urbano satisfaça as necessidades do patrimônio cultural e natural é necessário um planejamento estratégico que busque a compreensão do que as espécies vegetais destes locais significam para patrimônio, cultura e biodiversidade, e se realizem a avaliação, monitoramento e manejo adequados. Nesse sentido, o planejamento está relacionado intimamente com a gestão e conservação, fazendo-se necessário também a representação espacial dos dados das árvores, assim como as informações sobre as áreas de interesse e intervenção, baseados em pesquisas sólidas, dados quali-quantitativos, ferramentas de mapeamento e percepção verde e processos de implementação na prática.

Nesse contexto, temos como exemplo Melbourne e Sydney, na Austrália, que fazem parte das 10 cidades mais habitáveis do mundo, de acordo com um índice chamado "Liveability", do instituto de pesquisa Economist Intelligence Unit da revista The Economist. As cidades ocupam a segunda e terceira posição no ranking, respectivamente (EIU, 2019). Diante disto, foram analisadas, como exemplos, as estratégias e ferramentas destes locais e também as ferramentas utilizadas em Nova York e o índice de visão de verde desenvolvido pelo MIT.

Os instrumentos para gestão da arborização na cidade de Melbourne abordam diversas escalas de planejamento, considerando a cidade como um todo, setores, bairros e ruas. O plano também realiza uma revisão histórica dos boulevards da cidade para garantir a manutenção de sua integridade e identidade. Tal planejamento é realizado por meio de 10 planos distritais que são os Urban Forest Precinct Plans, presentes no documento "Urban Forest Strategy", onde cada um 


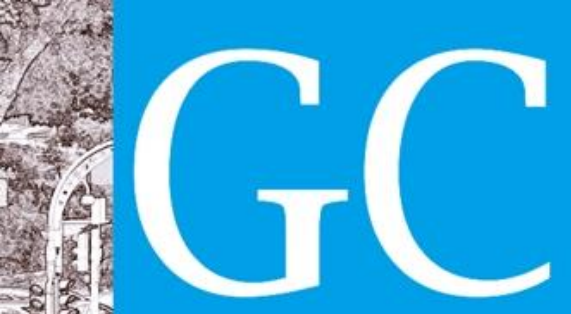

Revista Nacional de

Gerenciamento de Cidades

contém o mapeamento e análise SIG das condições da arborização de ruas com aspectos específicos, a fim de priorizar e concentrar os recursos nos locais que têm mais necessidade (FIGURA 1).

Além disso, a cidade também possui uma série de outros planos, manuais e guias, que sustentam, informam e funcionam como documentos complementares de apoio à implementação da cobertura vegetal na cidade. Tais informações são disponibilizadas de forma acessível para a sociedade e, desse modo, poderá contribuir para a educação ambiental da comunidade, no que se refere à importância da arborização urbana e as maneiras de proteger esses recursos para as futuras gerações.

Dos dez planos distritais, apresenta-se na Figura 1 as camadas de informações contidas no plano para o distrito de Carlton, onde se destacam os fatores considerados para priorização do plantio de árvores nas ruas, são eles: ruas com oportunidades de plantio ou substituição; alta densidade (> 20) de residentes vulneráveis ( $<5$ ou $>74$ anos); prioridade identificada pela comunidade para a arborização; ruas quentes e muito quentes; substituições de árvores necessárias nos próximos 10 anos; cobertura vegetal $<20 \%$.

Figura 1: Fatores para priorização do plantio de árvores nas ruas

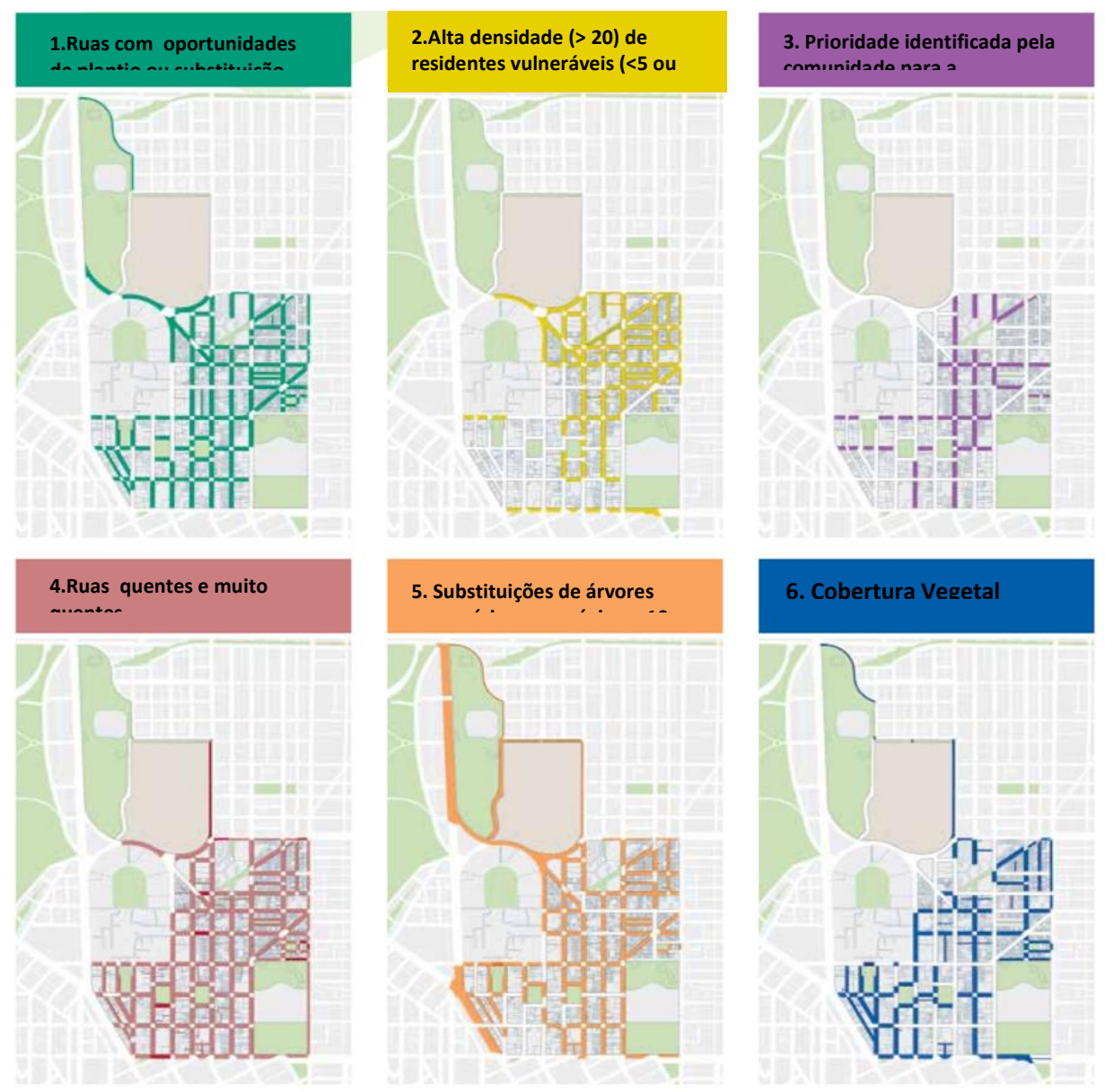

Fonte: CARLTON URBAN FOREST PRECINCT PLAN, 2013, adaptado pelos autores 2020. 


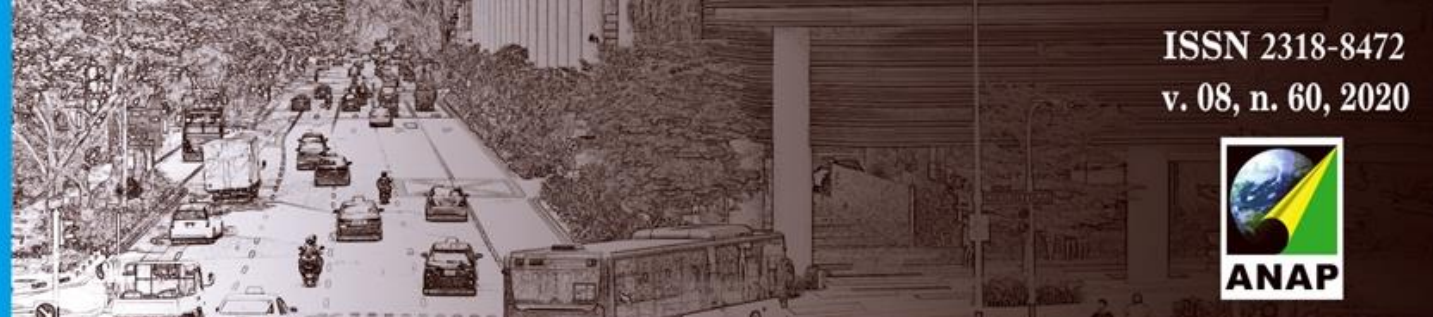

Revista Nacional de

Gerenciamento de Cidades

A cidade de Sydney, por sua vez, também possui diretrizes para a implementação da arborização urbana, que estão presentes no The Urban Forest Strategy, documento de apoio ao plano de ação e estratégias ambientais, considerando os anos de 2016 até 2021 (The Environmental Action 2016 2021 Strategy and Action Plan). Os objetivos fundamentais para atender as estratégias são: proteger e manter a arborização urbana, aumentar a cobertura vegetal, melhorar a diversidade das espécies, potencializar o conhecimento da sociedade sobre os benefícios daquela vegetação e o engajamento nos processos de planejamento (SYDNEY, 2013).

Assim como Melbourne, o documento de estratégias de Sydney para a arborização urbana também se relaciona com outros planos complementares, como o gerenciamento e avaliação das árvores no espaço urbano, guias técnicos de plantio e seleção de espécies, entre outros. Neste plano estratégico é proposto que para que um manejo sustentável da arborização urbana seja eficiente, aspectos como a manutenção da biodiversidade, capacidade de regeneração e potencial para cumprir funções ecológicas, econômicas e sociais devam ser englobados. As árvores localizadas nas ruas da cidade, parques e espaços abertos são avaliadas anualmente e essas informações estão contidas em um banco de dados regularmente atualizado, com apontamento de localização, espécie, tamanho, saúde, condição e registro dos trabalhos de manutenção já realizados. (SYDNEY, 2013). No que diz respeito a banco de dados, gerenciamento de informações e ferramentas tecnológicas para auxiliar os planos de arborização, aparecem também estudos em Nova York e no Instituto de Tecnologia de Massachusetts (MIT), em duas abordagens diferentes que serão detalhados adiante.

\section{FERRAMENTAS DE AVALIAÇÃO DA ARBORIZAÇÃO URBANA}

Como observado nos Planos de Arborização mencionados anteriormente, o estabelecimento de medidas decisivas para a preservação de áreas verdes urbanas é facilitado quando se dispõem de dados que determinam a sua exata localização e a sua real superfície, permitindo futuros estudos ecológicos urbanos (LOMBARDO, 1985). Portanto, a capacidade de quantificar com precisão as questões relativas à arborização urbana, em grandes cidades, é vital para determinar os serviços prestados e avaliar a eficácia das medidas adotadas.

O documento Urban Forest Strategy, que contém estratégias para a arborização urbana de Melbourne (MELBOURNE, 2012), estabeleceu uma série de processos e ferramentas para medir e modelar o potencial futuro desses elementos vegetais na cidade, que foram:

- A coleta de dados em campo, que forneceu uma fonte rica de informações relacionados às árvores e seu ambiente;

- O mapeamento espacial e temporal usando o ArcGIS, que permite determinar quais árvores perderemos, onde, quando e quanto a copa das árvores diminuirá;

- Ferramentas geoespaciais, como Lidar, Quickbird e Fotografia aérea de alta resolução, que permitem analisar a heterogeneidade espacial, a estrutura, composição e saúde da vegetação e o armazenamento de carbono; 


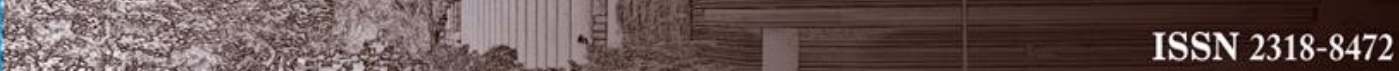

Revista Nacional de Gerenciamento de Cidades

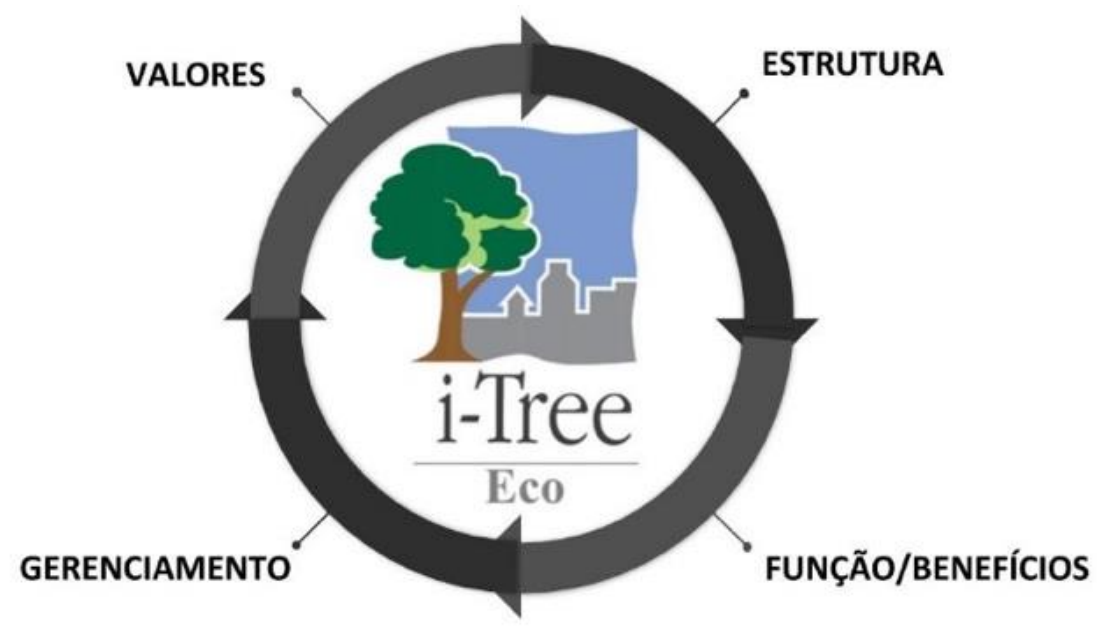

Fonte: Elaborado pelos autores, 2020.

A Aliança Nacional das Florestas Urbanas (NUFA) e a Arboricultura Austrália fizeram parceria de cooperação para o desenvolvimento e contextualização do i-Tree Eco para uso australiano. Atualmente, a cidade de Melbourne avaliou mais de mil árvores usando essa ferramenta, que também foi utilizada em seu plano de arborização.

Da mesma maneira, na cidade de Sydney a proteção da arborização tem prioridade em todos os aspectos das atividades da cidade e também utilizam o programa $i$-Tree, adaptado ao contexto australiano, para medir o desempenho do dossel da vegetação de porte arbóreo no meio urbano. De acordo com o documento das estratégias para a arborização urbana da cidade, isso ajudará a alcançar, monitorar e comunicar os objetivos e metas para 2021 (SYDNEY, 2013).

O uso e desenvolvimento contínuos de ferramenta é considerado como críticos para avaliar e medir os benefícios da arborização urbana na Austrália. As gestões das cidades estudadas utilizam desse conhecimento para garantir que estão no caminho adequado para alcançar os objetivos propostos, metas e visões a curto, médio e3 longo prazo.

O i-Tree Eco aparece também como ferramenta para calcular os benefícios ecológicos econômicos de cada árvore existente nas ruas da cidade de Nova York. As informações são disponibilizadas no site interativo, o New York City Street Tree Map, além disso, a ferramenta tem como proposta incentivar a participação e cuidado por parte da comunidade. O site contém informações estatísticas com os dados da quantidade de árvores mapeadas, atividades de manejo relatadas, árvores favoritas eleitas no próprio site pelos visitantes, número de espécies e a espécie predominante na cidade. A página ainda possibilita que os visitantes acompanhem as atividades recentes de cuidados e acesso ao inventário das espécies com as informações sobre cuidados, grupos de manejo, calendário de rega e os benefícios ecológicos anuais (águas pluviais interceptadas, energia conservada, poluentes removidos, dióxido de carbono reduzido e valor anual total dos benefícios), envolvendo a população local a participar e cuidar do patrimônio ambiental (FIGURA 5 e 6). 


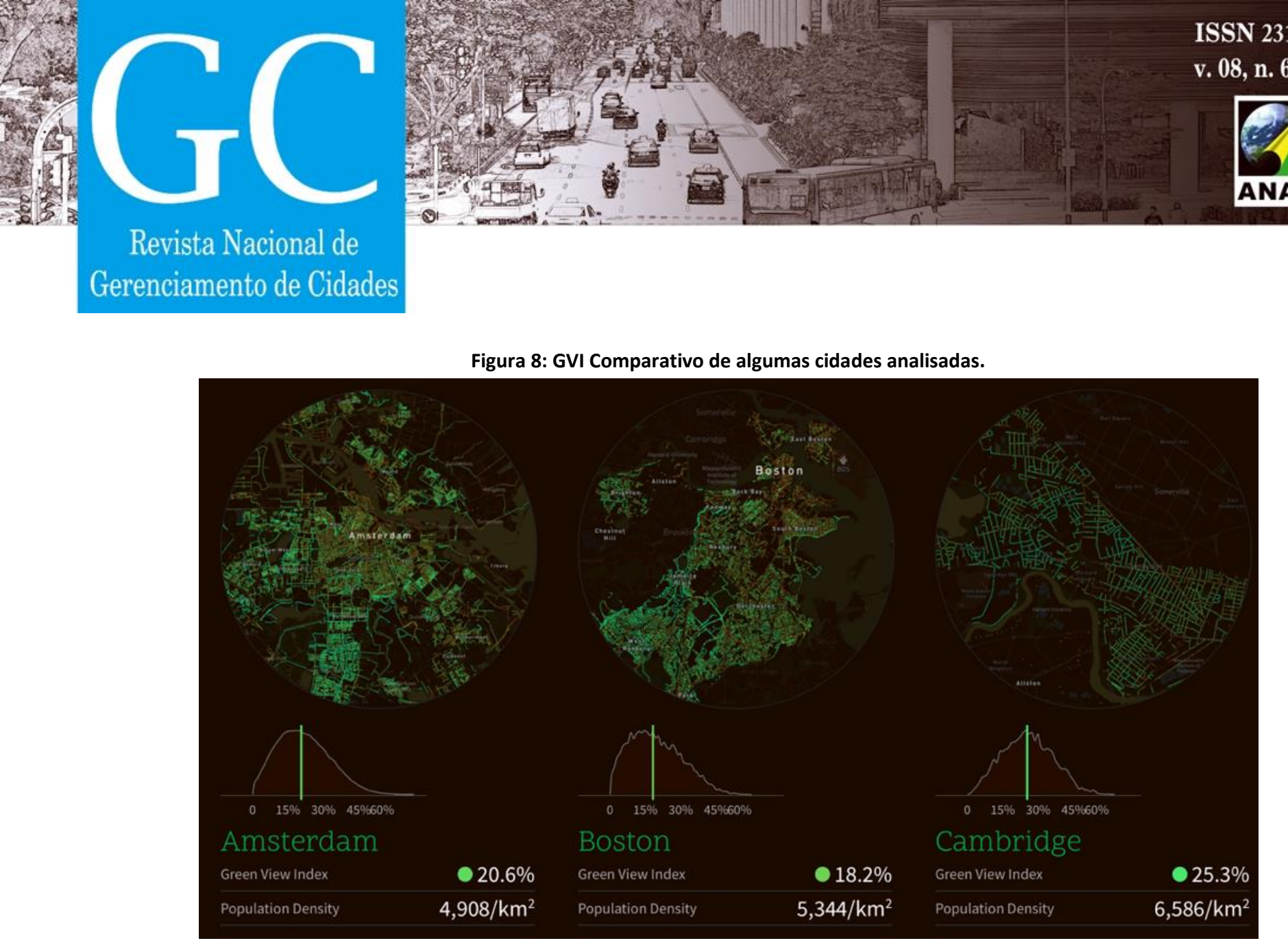

Fonte: TREEPEDIA, 2019.

A quantificação da percepção foi possível graças aos avanços recentes em "aprendizagem profunda", que permitiram quantificar as métricas urbanas em alta resolução e em grandes extensões, usando imagens no nível da rua. O termo "aprendizagem profunda" ou "deep learning" é utilizado para designar um ramo de aprendizado de máquina baseado em um conjunto de algoritmos que tentam modelar abstrações de alto nível de dados, usando um grafo profundo com várias camadas de processamento, composto de várias transformações lineares e não lineares (FIGURA 9). 
